\title{
Aid organizations tap into social-science expertise
}

\section{Behavioural and cultural studies seen as key to success of public-health initiatives.}

\section{BY ERIKA CHECK HAYDEN}

$\mathrm{C}$ ondoms. Breastfeeding. Hand washing. After a decade of ramped-up spending, the donors to global-health programmes are grappling with a thorny issue: why are some health-care interventions that are proven life-savers failing to save as many lives as they should in the field, even after unprecedented investment to support them?

The question topped the agenda at a meeting last week of industry executives, researchers, public-health workers and global-health campaigners convened by the Bill \& Melinda Gates Foundation in Seattle, Washington. The foundation is looking to enlist insights from the behavioural and social sciences to help in two key areas: helping communities to adopt proven interventions, and scaling these measures up to help more people in poor countries.

In the past, the foundation has invested heavily in developing technological innovations but comparatively little on persuading people to embrace them. It is now changing that by commissioning reports on how to build social and behavioural research into future development programmes to make them more successful. Foundation officials say that they are also considering these issues at each step in programmes already under way. The changes were spurred by discouraging reports such as one published in September (R. Lozano et al. Lancet 378, 1139-1165; 2011). This found that only 9 out of 137 developing countries are on track to meet two ambitious targets under the United Nations' Millennium Development Goals: to reduce maternal deaths by threequarters and child deaths by two-thirds by 2015 .

\section{"We may have the best malarial bed net, but if people don't sleep under it, it's not going to make a difference."}

Many treatments, such as oral-rehydration therapy to treat diarrhoea, or 'kangaroo mother' care, in which premature infants are held in skin-to-skin contact with their carer, are inexpensive and simple, but cultural and behavioural factors have slowed their adoption. "There isn't anything we do in global health that doesn't have some component of social change," Melinda

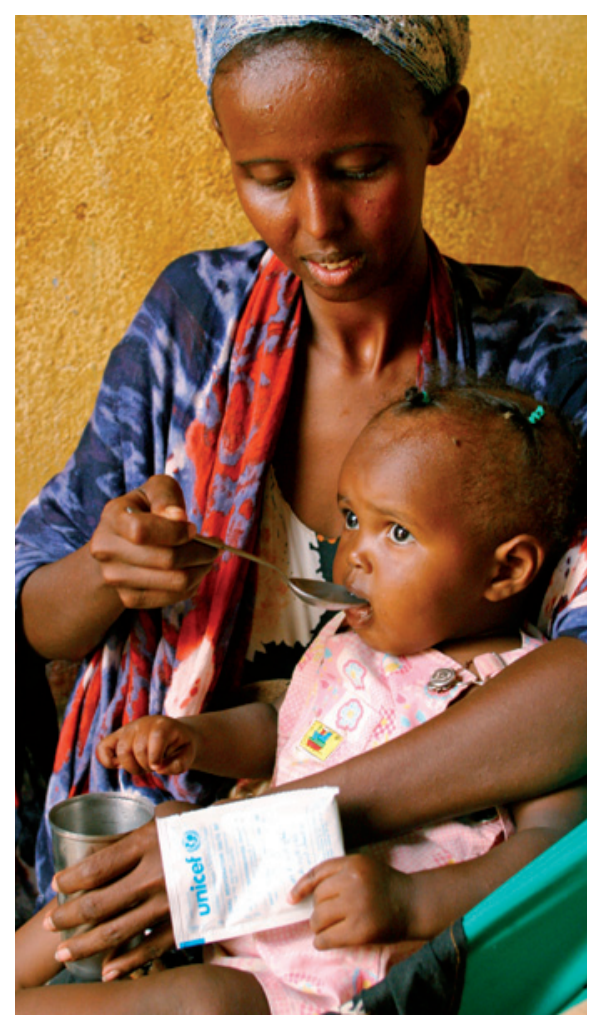

Oral rehydration is a cheap and simple life-saver.

Gates told delegates in her opening address. "We may have the best malarial bed net, but if people don't sleep under it, it's not going to make a difference."

Participants at the meeting cited numerous examples of how common sense and local knowledge could help to overcome barriers. Rashad Massoud, director of the USAID Health Care Improvement Project in Bethesda, Maryland, described a programme in Niger that aimed to prevent deaths from post-partum haemorrhage using the drug oxytocin. The programme was failing because oxytocin, which must be refrigerated, was delivered at night, when health-centre pharmacies were closed and could not accept deliveries. Public-health workers urged local communities to come up with their own solutions, such as using coolers to store the medicine, and maternal deaths from haemorrhage plummeted.

"A lot of the solutions we've figured out have come from communities themselves," noted Nana Twum-Danso, who directs African operations for the non-profit Institute for Healthcare Improvement in Cambridge, Massachusetts. She told the story of a project aimed at convincing women in Ghanaian villages to go to clinics to have their babies. Project leaders learned that women were reluctant to do this because it was perceived as cowardly. The villagers themselves came up with solutions to the problem, one of which was to fine men whose wives gave birth at home.

Gary Darmstadt, director of family health at the Gates Foundation, said that marketing expertise could also help. The private sector has experience in assessing markets' openness to new products and finding ways to get consumers to demand those products, he says. Such an approach might help the foundation to achieve its goals in cases such as promoting use of the antiseptic chlorhexidine to cleanse a newborn's umbilical cord to prevent infection. This has proved a challenge because many cultures have traditions surrounding the umbilical cord, such as smearing it with cow dung, oils or ash. "We're looking at how we design a product that makes people want to buy it and put it on, and these are the kinds of things that public health really hasn't done," Darmstadt said.

At the meeting, Donald Berwick, head of the US Centers for Medicare and Medicaid Services, in Baltimore, Maryland, praised the foundation for focusing attention on how to scale up proven health-care interventions. This could inspire a worldwide change, even in developed countries such as the United States, whose own health-care system is in "crisis", he said.

"If the Gates Foundation is interested in this, it will change the world," Berwick said. -

\section{CORRECTIONS}

The News story 'Mental-health guide accused of overreach' (Nature 479, 14; 2011) wrongly stated that the DSM-5 petition was sponsored by the American Psychological Association. It was co-sponsored by five divisions of the association, not the association as a whole.

The News Feature 'The Black Death decoded' (Nature 478, 444-446; 2011) wrongly located Sharon DeWitte at the State University of New York. She is now at the University of South Carolina in Columbia. 